\title{
Materiais adulterantes em amostras de Coffea sp. (Rubiaceae) e Curcuma longa (Zingiberaceae) obtidas em feiras livre de Goiânia, Goiás
}

\author{
Adulterant materials in samples of Coffea sp. (Rubiaceae) and Curcuma longa (Zingiberaceae) \\ obtained in open markets in Goiânia, Goiás \\ Materiales adulterantes en muestras de Coffea sp. (Rubiaceae) y Curcuma longa (Zingiberaceae) \\ obtenidas en mercados abiertos en Goiânia, Goiás
}

Recebido: 26/02/2021 | Revisado: 04/03/2021 | Aceito: 12/03/2021 | Publicado: 19/03/2021

\author{
Bárbara Feranandes da Silva \\ ORCID: https://orcid.org/0000-0002-2194-2596 \\ Universidade Federal de Goiás, Brasil \\ E-mail: barbarafernandes.s@hotmail.com \\ José Realino de Paula \\ ORCID: https://orcid.org/0000-0002-4424-7692 \\ Universidade Federal de Goiás, Brasil \\ E-mail: jose_realino@ufg.br \\ Camila Aline Romano \\ ORCID: https://orcid.org/0000-0002-3564-6368 \\ Universidade Federal de Goiás, Brasil \\ E-mail: camilaalineromano@gmail.com
}

\begin{abstract}
Resumo
A comercialização de produtos naturais é uma prática cultural importante pois, através desta prática o uso de plantas medicinais é amplamente difundido. O uso de plantas com finalidade terapêutica requer a aquisição de matérias primas corretamente identificadas e preparadas com critérios de qualidade para que possam ser utilizados com segurança pela população. Problemas comuns associados ao consumo das matérias primas de origem vegetal estão associados a falta de controle de qualidade e presença de adulterantes. Considerando a importância do comércio de drogas vegetais para a população e os riscos que matérias inadequadas para o uso podem trazer riscos à saúde humana, o presente estudo se propôs investigar a qualidade de matérias primas de Curcuma longa (açafrão-da-terra) e Coffea sp. (café), bem como a identificação e presença de adulterantes em amostras comercializados nos centros de abastecimento de Goiânia-Goiás. As amostras foram obtidas comercialmente de modo aleatório em feiras e centros de abastecimento. Foram obtidas 20 amostras de C. longa e 14 de Coffea sp. Na avaliação dos parâmetros de qualidade, as matérias primas estavam adequadas quanto a umidade e teor de voláteis, bem como na presença de cinzas. Entretanto, a pesquisa de material estranho revelou que mais de 50\% das amostras apresentavam materiais estranhos utilizados como adulterantes, geralmente para aumentar o peso do material. De acordo com os resultados obtidos, verificou-se falhas no processo de comercialização de café e açafrão da terra, visto que foram identificadas matérias estranhas nas amostras colhidas de ambas espécies, de forma a demonstrar que a ausência de fiscalização pode ser prejudicial aos consumidores física e economicamente.
\end{abstract}

Palavras-chave: Controle de qualidade; Plantas alimentícias; Produtos naturais.

\begin{abstract}
The commercialization of natural products is an important cultural practice because, through this practice, the use of medicinal plants is widespread. The use of plants for therapeutic purposes requires the acquisition of raw materials correctly identified and prepared with quality criteria so that they can be used safely by the population. Common problems associated with the consumption of raw materials of plant origin are associated with the lack of quality control and the presence of adulterants. Considering the importance of the trade in plant drugs for the population and the risks that materials unsuitable for use may pose risks to human health, the present study set out to investigate the quality of raw materials of Curcuma longa (turmeric) and Coffea sp. (coffee), as well as the identification and presence of adulterants in samples sold in the supply centers of Goiânia-Goiás. The samples were obtained commercially at random from fairs and supply centers. Twenty samples of C. longa and 14 of Coffea sp. In the evaluation of quality parameters, the raw materials were adequate in terms of moisture and volatile content, as well as in the presence of ash. However, research on foreign material revealed that more than $50 \%$ of the samples had foreign materials used as adulterants, usually to increase the weight of the material. According to the results obtained, there were flaws in the process of commercializing coffee and saffron, since foreign matter was identified in samples taken from both species, in order to demonstrate that the lack of inspection can be harmful to consumers and economically.
\end{abstract}


Keywords: Quality control; Food plants; Natural products.

\section{Resumen}

La comercialización de productos naturales es una práctica cultural importante porque, a través de esta práctica, el uso de plantas medicinales está muy extendido. El uso de plantas con fines terapéuticos requiere la adquisición de materias primas correctamente identificadas y preparadas con criterios de calidad para que puedan ser utilizadas con seguridad por la población. Los problemas habituales asociados al consumo de materias primas de origen vegetal están asociados a la falta de control de calidad y la presencia de adulterantes. Teniendo en cuenta la importancia del comercio de medicamentos vegetales para la población y los riesgos de que los materiales no aptos para su uso puedan generar riesgos para la salud humana, este estudio tuvo como objetivo investigar la calidad de las materias primas de Curcuma longa (cúrcuma) y Coffea sp. (café), así como la identificación y presencia de adulterantes en muestras vendidas en los centros de abastecimiento de Goiânia-Goiás. Las muestras se obtuvieron comercialmente al azar de ferias y centros de abastecimiento. Veinte muestras de C. longa y 14 de Coffea sp. En la evaluación de los parámetros de calidad, las materias primas resultaron adecuadas en términos de humedad y contenido de volátiles, así como en presencia de cenizas. Sin embargo, la investigación sobre material extraño reveló que más del $50 \%$ de las muestras tenían materiales extraños utilizados como adulterantes, generalmente para aumentar el peso del material. De acuerdo con los resultados obtenidos, existieron fallas en el proceso de comercialización de café y azafrán, ya que se identificó materia extraña en muestras tomadas de ambas especies, con el fin de demostrar que la falta de inspección puede ser perjudicial para los consumidores y económicamente.

Palabras clave: Control de calidad; Plantas alimenticias; Productos naturales.

\section{Introdução}

A etnobotânica e a fitoterapia são áreas de estudo responsáveis por grande parte do conhecimento a respeito da utilização de plantas atualmente. Trata-se de etnobotânica o modo como as crenças populares são adquiridas e como são repassadas ao longo do tempo, já a fitoterapia dá ênfase ao grupo de plantas que possuem propriedades farmacológicas e às técnicas necessárias para obtenção de seus fitofármacos (Marchi et al., 2016). Uma figura importante para os estudos das plantas é o raizeiro, responsável por repassar informações a respeito de dosagem e posologia de acordo com conhecimento popular em mercados, feiras e pequenas lojas (Freitas 2012). O comércio de plantas em supermercados está sujeito à fiscalização da Agência Nacional de Vigilância Sanitária (Brasil, 2014), de forma que estes produtos sejam oferecidos sem adulterantes. Por outro lado, os produtos vendidos em mercados municipais, feiras livres ou por raizeiros não são submetidos às análises e estão propensos a sofrerem alterações em suas características, como a inserção de adulterantes ou contaminação resultante de um processamento ineficiente. Dois exemplos de espécies de importância econômica, social e farmacológica são o açafrão-da-terra (Curcuma longa, L - Zingiberaceae) e o café (Coffea sp. - Rubiaceae).

C. longa tem origem indiana e distribuição mundial historicamente realizada pelos espanhóis. Possui cor amarelo brilhante e a parte mais utilizada é o seu rizoma. Sua importância está relacionada ao uso do óleo essencial em perfumaria e dos rizomas triturados (pó) como corante, componente de sopas desidratadas e do condimento curry (Milhomem \& Teixeira, 1997). Além disso, é mundialmente conhecido por suas propriedades terapêuticas, cosméticas, dermatológicas e religiosas, devido à sua alta disponibilidade e baixo custo (Moretes \& Geron, 2019). Anteriormente, seu uso estava associado a alguns rituais religiosos, mas também era considerado o único meio tradicional de prevenção e/ou tratamento de patologias e lesões dentro de comunidades tradicionais (Firmo et al., 2011; Carvalho 2012; Giraldi \& Hanazaki, 2010). Seu uso na medicina Ayurveda ocorre a há 6.000 anos, com prescrição especialmente associada às afecções das vias aéreas, como resfriados e sinusite, além de infecções bacterianas, alterações hepáticas, diabetes, feridas, reumatismo, anorexia; a parte da planta que deve ser usada são os rizomas (Wang et al., 2014; Almeida 2006; Araujo \& Leon, 2001).

Os constituintes químicos do óleo essencial de $C$. longa são predominantemente sesquiterpenos oxigenados, o que lhe confere característica aromática. Além disso, compostos de curcuminoides, responsáveis pela pigmentação dos rizomas, são abundantes sedo a curcumina a principal substância ativa (60 a 76\%). Outros constituintes como: carbinol, resina, amido, polissacarídeos, sais de potássio e açúcares fazem parte da sua constituição (Alonso 1998; Bastos et al., 2009; Grandi 2014). 
Devido a sua diversidade de metabólitos, muitas pesquisas ressaltaram diferentes propriedades farmacológicas da C. longa, dentre elas, antidiarreicas, diuréticas, antiescorbúticas, antiespasmódicas, hepatoprotetoras, anti-HIV, antiparasitários, inibidor da carcinogênese, anti-inflamatórias, antibacterianas, antivirais, antifúngicas e antitumorais, além anticonvulsivantes, antiartríticos, redutor do nível de colesterol, sedativo e imunomodulação, antioxidante e neuroprotetora (Alonso 1998; Araujo \& Leon, 2001; Yu et al., 2002; Almeida 2006; Bastos et al., 2009; Grandi 2014; Kim et al., 2014; Alonso 2016).

De igual modo, Coffea sp. também tem grande relevância para a população mundial social e econômica A cultura do café foi introduzida no Brasil meados de 1700. Os cafezais possibilitaram o aumento da exportação e geração de empregos, alavancando a economia interna (Fassio \& Silva, 2007). Ademais, o café é objeto de estudo de diversas áreas incluindo a etnobotânica e a farmacologia a fim de estabelecer seus principais aplicações e benefícios (Lima 1989). De acordo com a literatura, o café apresenta eficácia para combater a depressão, aliviar o estresse e prevenir alguns tipos de câncer (Almeida $e t$ al., 2003; Lima 2003).

Através do processo de infusão dos grãos moídos e torrados, a bebida tornou-se conhecida por seu papel estimulante em resposta a presença da cafeína, mas também ganhou espaço ao serem identificados constituintes químicos presentes no grão de café, como os ácidos clorogênicos, que possuem propriedades antioxidantes, conferindo um papel importante na saúde humana (Alves et al., 2009). O estudo de Almeida (2003) mostrou que Coffea sp. pode reduzir o risco de alguns tipos de câncer, devido à presença de substâncias antioxidantes, anticarcinogênicas e antiteratogênicas presentes no café ou formadas durante o seu processamento. Além disso Lima (2003), demonstrou que com o consumo moderado do café aumenta a concentração e a disposição diária além de reduzir a apatia e a depressão.

Com isso, o objetivo desse trabalho foi de verificar a confiabilidade dos produtos vendidos em feiras e mercados municipais através de experimentações em laboratório que revelem se sua composição de origem é mantida, desde o processamento até a chegada ao consumidor. Desta forma, visa-se atestar a ausência ou presença de adulterações através de experimentações, microscópicas e macroscópicas, feitas em drogas vegetais adquiridas aleatoriamente no município de Goiânia.

\section{Metodologia}

\subsection{Obtenção das amostras}

Amostras de Coffea sp. e C. longa foram obtidas em mercados e feiras livres em diferentes bairros da cidade de Goiânia, Goiás, Brasil. A obtenção do material foi realizada de modo aleatório. Foram adquiridas 100g de amostra de cada local. A etapa de controle de qualidade das amostras foi realizada no Laboratório de Pesquisa em Produtos Naturais da Faculdade de Farmácia, Universidade Federal de Goiás. Os critérios utilizados nessa avaliação, bem como nas etapas subsequentes, estão descritos na Farmacopéia Brasileira (Brasil 2019).

\subsection{Determinação de teor de voláteis}

O processo de determinação de teor de voláteis se baseou no resultado da pesagem em triplicata um valor entre e $0,5 \mathrm{~g}$ e $1 \mathrm{~g}$ em uma balança de aquecimento halógeno $\left(\right.$ Ohaus $\left.^{\circledR}\right)$ e obtenção do teor de umidade.

\subsection{Determinação de cinzas totais}

A determinação de cinzas totais é um processo no qual é feito a calcinação dos cadinhos vazios, para calibração e obtenção de seu peso. Em seguida, em duplicata, foi pesado $3 \mathrm{~g}$ de amostra para que pudessem ser calcinados, por fim o peso do cadinho vazio é descontado do peso final. 


\subsection{Cromatografia de Camada Delgada}

Para as amostras de $C$. longa realizou-se ainda a Cromatografia de Camada Delgada (CCD). Para isso, extraiu-se 0,5 g de amostra em $5 \mathrm{~mL}$ de metanol, sob agitação, por $30 \mathrm{mim}$. A amostra foi centrifugada a $116 \mathrm{x} \mathrm{g}$ por $10 \mathrm{mim}$. O extrato obtido foi aplicado em cromatoplaca de sílica gel GF254. A eluição da placa cromatográfica, foi realizada com fase móvel composta por clorofórmio, álcool etílico e ácido acético glacial (95:5:0,5). As amostras foram reveladas sob luz ultravioleta a $\lambda=365 \mathrm{~nm}$.

\subsection{Descrição microscópica do açafrão}

Para descrição microscópica de C. longa, uma porção da amostra foi finamente espalhada sobre lâmina de microscopia e uma gota de Reagente de Steinmetz. Amostras positivas foram agrupadas qualitativamente quanto ao grau de adulteração como: pouco adulterado (+), razoavelmente adulterado (++) e muito adulterado (+++). Essa classificação foi estabelecida a partir da proporção entre grãos de amido de $C$. longa e grãos estranhos.

\subsection{Descrição em lupa estereoscópica do café}

A descrição microscópica do pó de Coffea sp. foi realizada em esteromicroscópio (Leica) com aumento de 20x. Nessa avaliação são investigadas a ocorrência de impurezas como fragmentos vegetais estranhos. Ela confirma a presença de adulterantes como grãos de milho, café, cevada, dentre outros, além de objetos não alimentícios como fragmentos de insetos, fios de tecido e pelos de animais que geralmente ocorrem em amostras adulteradas ou processadas sem controle de higiene. Nessa avaliação foram considerados os padrões microscópios descritos por Miranda (2014) e no Atlas de microscopia: café torrado e moído (Matos et al., 2012)

\subsection{Análise estatística}

Os dados gerados a partir da análise de parâmetros quantitativos como teor de umidade e cinzas totais foram comparados por teste $t$ (Student) considerando significativos os valores com valor de $p<0,005$. A análise estatística foi realizada com auxílio do software Biostat (Ayres et al., 2007)

\section{Resultados e Discussão}

O teor de umidade obtido mostra que 57,14\% das 14 amostras de café analisadas não se encontram de acordo com o padrão estabelecido pela ANVISA (Brasil 2019), o mesmo foi observado no trabalho de Silva (2019) que analisou amostras embaladas e a granel e também encontrou desconformidades com as normativas que estabelecem um teor de umidade de no máximo 5\%. A média de cada triplicata mostra que o valor $42,85 \%$ das amostras estão sob condições adequadas. A Sociedade Brasileira de Farmacognosia estabelece o limite de umidade entre 8\%-12\% para drogas vegetais, $C$. longa se enquadrou nessa classificação e apenas duas amostras apresentaram umidade abaixo de 8\%. Ferreira (2018) observou que as amostras de açafrão-da-terra geralmente estão em conformidade com os limites estabelecidos tanto pela ANVISA quanto pela Farmacopeia quando se trata do limite de umidade. 
Tabela 1. Valores percentuais médios de teores de umidade, cinzas totais e materiais estranhos das amostras de Curcuma longa(açafrão-da-terra) e Coffea sp. obtidos nas feiras livres de Goiânia-Goiás. *valor máximo permitido.

\begin{tabular}{llll}
\hline & Título & & \\
\cline { 2 - 4 } Matéria prima & Teste & Valor Médio \pm DP $(\%)$ & VMP $(\%) *$ \\
\hline \multirow{2}{*}{ C. longa } & Teor de umidade & $8.2 \pm 0,8$ & 12 \\
& Cinzas Totais & $4.9 \pm 1,6$ & 8 \\
& Material Estranho & ++ & 5 \\
Coffea sp. & Teor de umidade & $4.7 \pm 0,7$ & 5 \\
& Cinzas Totais & $3.2 \pm 0,2$ & \\
\hline
\end{tabular}

Fonte: Autores.

As cinzas totais das amostras de café indicam que 100\% das amostras não ultrapassaram o limite de 5\% de cinzas totais estabelecido pela Associação Brasileira da Indústria do Café (ABIC 2018). Em contrapartida, C. longa apresentou 10\% de amostras acima do limite de 8\% de umidade preconizada pela Farmacopéia Brasileira (Brasil 2019), conforme pode ser observado na Figura 1.

Figura 1. Cinzas totais das amostras de Coffea sp. (A, B, C) e Curcuma longa (D, E, F).

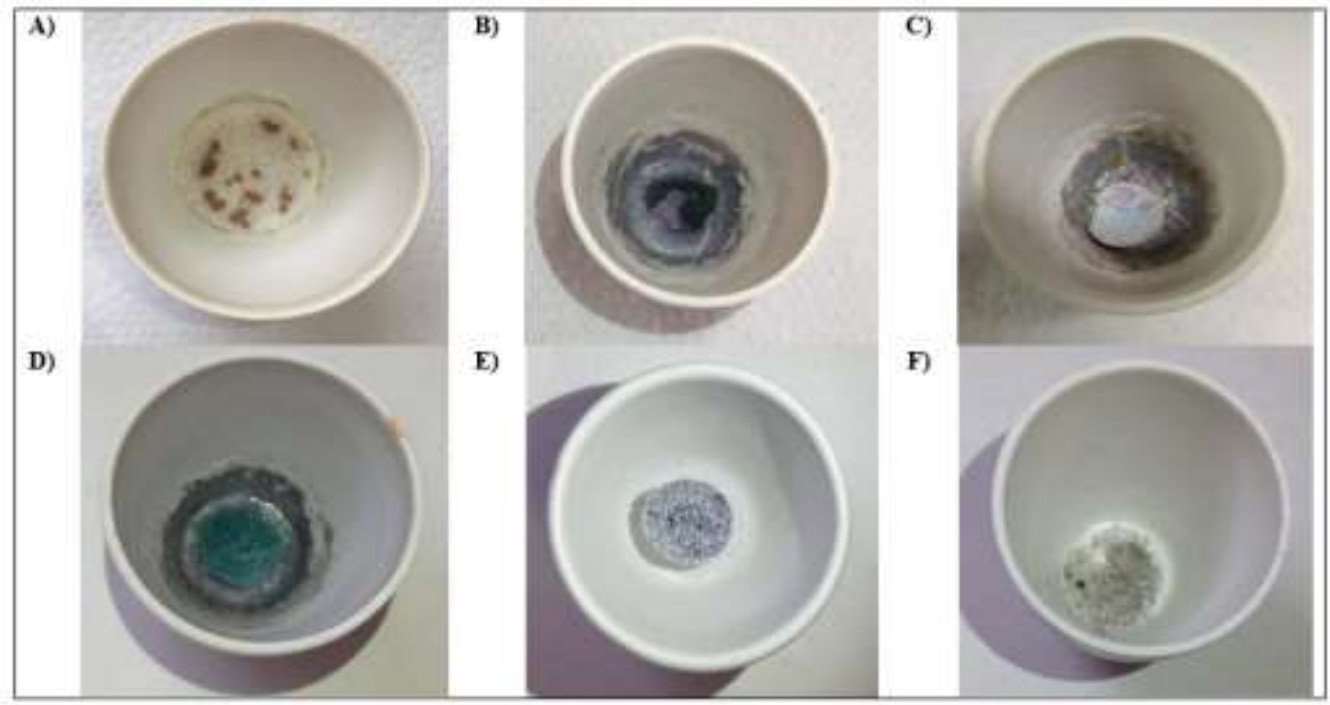

Fonte: Autores.

A cromatografia em camada delgada (CCD) revelou a separação da curcumina, demetoxicurcumina e bisdemetoxicurcumina (Figura 1 "a" e "b") componentes presentes no açafrão de acordo com a Farmacopeia Brasileira (Brasil 2019), e identificadas em comparação com solução padrão das substâncias. A detecção desses curcuminóides é utilizada há muitos anos como marcador para C. longa (Li et al., 2011; Windarsih et al., 2019). Nas amostras adulteradas, além da separação desses compostos, foi possível observar a eluição de outros compostos nos quais não foi possível observar separação (Figura 1 “c”). Tal fato evidencia a presença de componentes não pertencentes ao açafrão-da-terra, confirmando a hipótese da presença de materiais adulterantes. Alves (2011) mostra como o uso das técnicas de CCD são úteis para os testes de controle de qualidade devido a fácil execução e confiabilidade, Souza-Moreira (2013) e Feltes \& Milão 2011 atestaram a eficácia da CCD e mostraram sua funcionalidade. Sen e colaboradores (1974) já utilizavam cromatografia em camada fina para separar amostras de C. longa, de outras espécies como Curcuma zedoaria e Curcuma aromatica, as quais tem perfis químicos muito próximos, o que torna a identificação das mesmas bastante truncada. Windarsih e companheiros (2019) utilizaram técnicas de 
CCD e Ressonância Nuclear Magnética ( $\left.{ }^{1} \mathrm{H}-\mathrm{RMN}\right)$ para separar amostras de C. longa adulteradas com Curcuma heyneana, associado a modelos estatísticos preditivos.

Além da cromatografia em camada delgada, a literatura apresenta outras análises que podem ser aplicadas à pesquisa por materiais adulterantes. Girme e companheiros (2020) aplicaram técnicas de quantificação de curcumina para avaliação da qualidade de amostras de C. longa por meio de Cromatografia Líquida de Alta Eficiência (CLAE) onde foi possível obter sensibilidade a partir de $1 \%$ de presença dos materiais adulterantes. Em meados dos anos 2000 já se empregava marcadores moleculares para detecção de adulterantes em C. longa (Sasikumar et al., 2007; Parvati et al., 2015).

Figura 2. Amostras do extrato metanólico de Curcuma longa submetidas a Cromatografia em Camada Delgada (CCD). As cromatoplacas "A" e "B" apresentam o resultado da eluição de amostras sem adulterantes. A cromatoplaca "C" apresenta uma amostra adulterada. Note o arraste provocado pela eluição de compostos não separáveis pela fase móvel padrão.

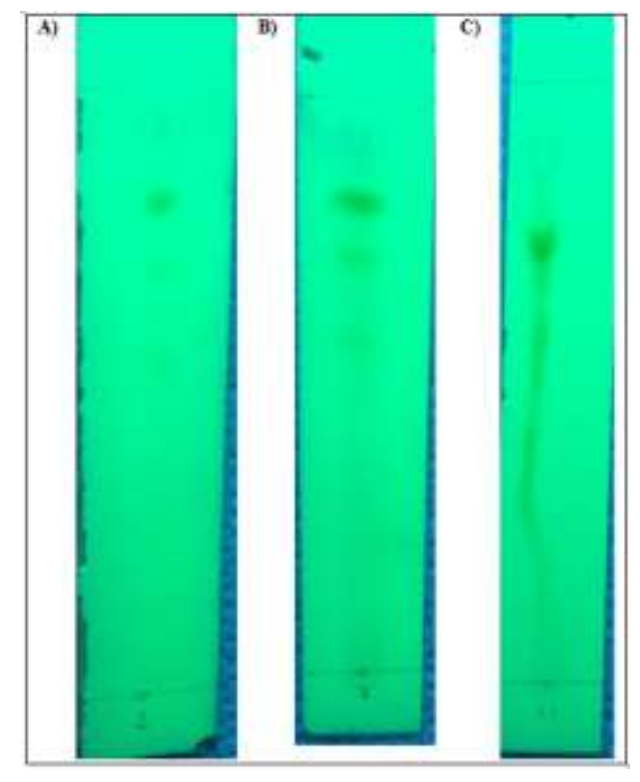

Fonte: Autores.

A microscopia de pó realizada com as amostras de C. longa permitiu a caracterização dos grãos de amido. Nessa avaliação observou-se um total de 49,5\% de amostras adulteradas com amido de milho, variando apenas na intensidade da ocorrência dos mesmos nas amostras (Figura 3). Não foram encontrados outros tipos de adulterantes nas amostras de $C$. longa. Provavelmente a adulteração com amido de milho está associada ao aumento de volume do material a ser vendido. O amido está entre os principais materiais adulterantes encontrados em $C$. longa, ele pode ser incorporado à droga vegetal tanto para aumentar o volume, como para melhorar a aparência do material, por exemplo (Sasikumar 2019). 
Figura 3. Amostras de Curcuma longa (açafrão-da-terra) com e sem presença de adulterantes. Em A) Amostra mostrando grãos de amido característicos do açafrão (*) e de milho (•); B) Amostra de açafrão-da-terra sem adulterantes; C) Grãos de amido de milho (padrão);

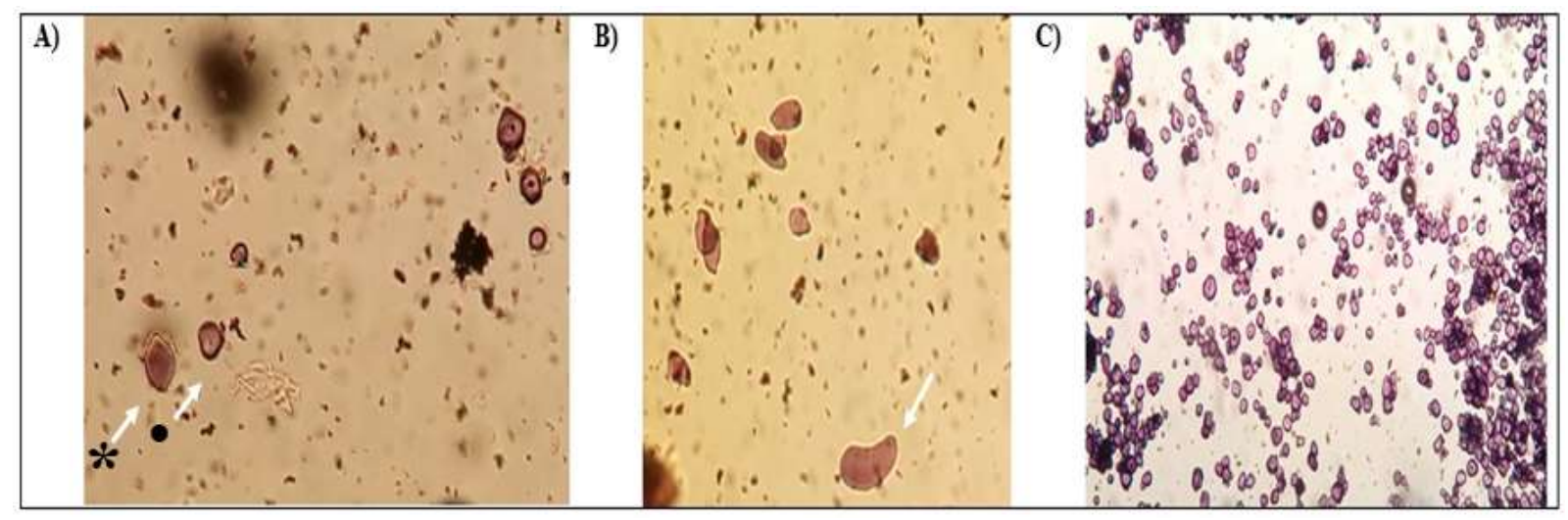

Fonte: Autores.

Adulterantes em amostras de Coffea sp., foram evidenciados quando observadas à lupa estereoscópica. Os principais adulterantes encontrados foram grãos de milho e resíduos vegetais. Mas algumas amostras ainda mostraram grãos de feijão e cascas de cevada, além de grãos não triturados do próprio café. Esses materiais também foram observados por Assis (2020), mas qualidade visual do material estranho foi comprometida de acordo com a torra do café (Figura 4). As altas torras favorecem a camuflagem dos adulterantes por esconderem suas características, de modo a passarem despercebidos entre os grãos. Segundo Toci e colaboradores (2015) os materiais adulterantes das amostras de café são adicionados na intenção de reduzir custos. A presença desses elementos adulterantes afeta diretamente nos aromas e na qualidade da bebida e, em decorrência há uma tendencia crescente no desenvolvimento de técnicas analíticas mais precisas que visem não somente a identificação, mas a quantificação de adulterantes em drogas vegetais. Tavares e colaboradores (2016) mostraram a eficiência da avaliação por CLAE tomando índices de tocoferol como marcadores da pureza do café. Segundo os autores, a presença de milho em níveis maiores que $10 \%$ e cascas a cima de $20 \%$ com cascas são suficientes para caracterizar o perfil químico da amostra adulterada. Reis e companheiros (2013) avaliaram o potencial preditivo da Espectroscopia por Transformada de Fourier no Infravermelho de Refletância Difusa (DRIFTS) associada a modelos estatísticos para discriminação de amostras de café adulteradas com habilidade de predição em 100\%. 
Figura 4. Amostras de Coffea sp. com presença de adulterantes. Em A) a seta indica presença de fiapos; B, C e F) a seta aponta a presença de grãos de milho; D) a seta indica presença de grãos de feijão: E) a seta indica fragmentos de madeira (cascas);

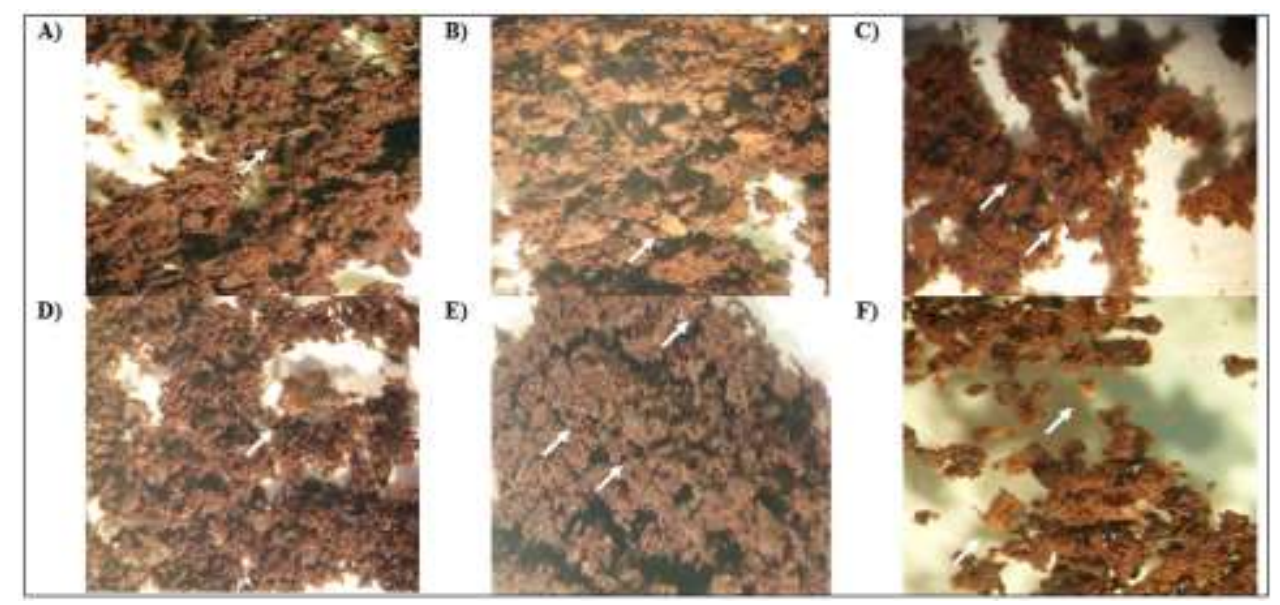

Fonte: Autores.

A avaliação estatística das médias obtidas a partir dos dados quantitativos do controle de qualidade indicou baixa significância, confirmando os dados que identificam pouca diferença entre as médias obtidas através da avaliação do teor de voláteis $(\mathrm{p}=9,992 ; \mathrm{t}=-11)$ e cinzas totais $(\mathrm{p}=9,992 ; \mathrm{t}=10)$ para amostras de $C$. longa, mostrou que é possível assumir a existência de uma amostra homogênea dentro dos parâmetros de qualidade. Valores também homogêneo foram notados para as amostras de Coffea sp. tanto no teor de voláteis $(\mathrm{p}=6,756 ; \mathrm{t}=13)$ como nas cinzas totais $(\mathrm{p}=3,200 ; \mathrm{t}=14)$, dessa forma é possível assumir a existência de uma amostra homogênea dentro dos parâmetros de qualidade. Entretanto, quando a morfologia microscópica é analisada, é possível identificar fraudes nos produtos comercializados.

\section{Conclusão}

Poucos trabalhos feitos com C. longa objetivaram investigar adulterações, uma possível resposta à essa escassez pode ser relacionada ao fato de que mesmo adulteradas as amostras possuem resultados satisfatórios nos testes de qualidade estabelecidos, de forma que a diferenciação se dá em sua maioria pela coloração, sabor e aroma. Além disso, para Coffea sp. notou-se que o grau de torra dos grãos altera a visibilidade e, consequentemente, a detecção de matérias estranhas; ainda que cinzas variou, de forma de inferir que a adulteração interfere na cor, mas para confirmação desses dados são necessários novos estudos. A literatura mostra um esforço para desenvolvimento de técnicas analíticas que sejam capazes de detectar adulterações com boa sensibilidade. A pesar da evolução dessas técnicas em muitos sentidos, algumas delas ainda requerem altos investimentos. Assim, as técnicas clássicas de controle de qualidade ainda são mais acessíveis e úteis para triagem qualitativa e detecção de matérias primas adulteradas.

\section{Referências}

ABIC. Associação Brasileira da Indústria de Café. (2020). Indicadores da Indústria de Café.

Almeida, A. A. P., Oliveira, L. S., Moraes Santos, T., \& Glória, M. B. A. (2003). Café e saúde: três décadas de estudos. Revista Brasileira de Armazenamento (Brasil). (Especial Café - no.7) 56-63.

Almeida, L. (2006). Caracterização de Pigmentos da Curcuma longa L.: Avaliação da Atividade Antimicrobiana, Morfogênese in vitro na Produção de Curcuminóides e Óleos Essenciais [dissertação]. Faculdade de Farmácia da Universidade Federal de Minas Gerais.

Alonso, J. (2016). Tratado de Fitofármacos e Nutracêuticos. A C Farmacêutica. 
Alonso, J. R. (1998). Tratado de fitomedicina: bases clinicas y farmacológicas. Isis.

Alves, M. M., Pereira, A. M. S., Pereira, P. S., França, S. C., \& Bertoni, B. W. (2011). Caracterização química de tinturas e extratos secos de plantas medicinais do Cerrado por cromatografia em camada delgada.7(12), 1-8p.

Alves, R. C., Casal, S., \& Oliveira, B. (2009). Benefício do café na saúde: Mito ou realidade.Química Nova, 32(8), 2169-2180p.

Araújo, C. A. C., \& Leon, L. L. (2001). Biological activities of Curcuma longa L. Mem. Inst. Oswaldo Cruz, 96(5):723-728.

Assis, N. M., Marques, C. A., \& Silva, M. C. (2020). Avaliação microscópica de amostras comerciais de café. Segur. Aliment. Nutr., $27,1-13$.

Ayres, M. Bioestat: aplicações estatísticas nas áreas de ciências biológicas e médicas. Belém: Sociedade Civil Mamirauá, MCT-CNPq, 2007. <https://www.mamiraua.org.br/downloads/>.

Bastos, D. H. M., Rogero, M. M., \& Arêas, J. A. G. (2009). Mecanismos de ação de compostos bioativos dos alimentos no contexto de processos inflamatórios relacionados à obesidade. Arq Bras Endocrinol Metab. 53(5): 646-656p.

Brasil. (2014). Agência Nacional de Vigilância Sanitária. Resolução da diretoria colegiada- Resolução - RDC No 26 , de 13 de maio de 2014.

Brasil. (2019). Farmacopéia Brasileira, (6a ed.), Agência Nacional de Vigilância Sanitária. Anvisa.

BrasiL. Ministério da Saúde. (2005). Resolução. RDC $n^{o}$ 277, de 22 de setembro de 2005. Regulamento Técnico para Café, Cevada, Chá, Erva-Mate e Produtos Solúveis; Diário Oficial da União. [Acesso em: 10 março 2020]

Carvalhos, J. C. T. (2012). Formulário Médico-Farmacêuticode Fitoterapia. (3a ed.), Pharmabooks, 365p.

Fassio, L. H., \& Silva, A. E. S. (2007). Importância econômica e social do café conilon. In: Ferrão, R. G., Fonseca, A. F., Bragança, S. M., Ferrão, M. A. G., Muner, L. H. Café conilon. Vitória, ES: INCAPER,p. 37-47.

Feltes, P. K., \& Milão, D. 2011. Controle de qualidade do radiofármaco fludesoxiglicose (18F): comparação prática entre os testes requeridos nas Farmacopéias Britânica, Européia e Americana. Revista da Graduação,4(20), p.4-6.

Ferreira, G. O., \& Lemes, L. F. N. (2018). Análise Farmacognóstica e de Rotulagem da Canela (Cinamomum cassia (L.) J. Presl) e do Açafrão (Curcuma longa L.), Comercializados como condimentos, em Valparaíso - GO. Revista de Medicina e Saúde de Brasília, 7(1):651-657p.

Firmo, W. C. A., Menezes, V. J. M., Passos, C. E. C., Dias, C. N., Alves, L. P. L., Dias, I. C. L., Neto, M. S., \& Olea, R. S. G. (2011). Contexto histórico, uso popular e concepção científica sobre plantas medicinais. Cad. Pesq. 18: 90-95p.

Freitas, A. V. L. (2012). Os raizeiros e a comercialização de plantas medicinais em SãoMiguel, Rio Grande do Norte, Brasil. Revista Brasileira de Biociências, 10(2):147-156p.

Giraldi, M., \& Hanazaki, N. (2010). Uso e conhecimento tradicional de plantas medicinais no Sertão do Ribeirão, Florianópolis, SC, Brasil. Acta Bot. Bras., 24(2): 395-406.

Girme, A., Saste, G., Balasubramaniam, A. K., Pawar, S., Ghule, C., \& Hingorani, L. (2020). Assessment of Curcuma longa extract for adulteration with synthetic curcumin by analytical investigations, Journal of Pharmaceutical and Biomedical Analysis, $191,113603$.

Grandi, T. S. M. (2014). Tratado das plantas medicinais: Mineiras, Nativas e Cultivadas. Adaequatio Estúdio, 1076-1077p.

Kim, M. H., Kim, S. H., \& Yang, W. M. (2014). Mechanisms of action of phytochemicals from medicinal herbs in the treatment of Alzheimer's disease. Planta Med, 80(15):1249-58.

Li, S., Yuan, W., Deng, G., Wang, P., Yang, P., \& Aggarwal, B. B. (2011). Chemical composition and product quality control of turmeric (Curcuma longa L.), Pharmaceutical Crops, 2, 28-54.

Lima, D. R. (2003). Café e Saúde: Manual de farmacologia clínica, terapeutica e toxicologia. Medsi Editora (3 volumes), 141-149p.

Lima, D. R. A. (1989). A Cafeína e sua saúde. Editora Record.

Marchi, J. P., Tedesco, L., Melo, A. C., Frasson, A. C., França, V. F., Sato, S. W., \& Wietzikoski, E. V. (2016). Curcuma longa- L., o açafrão da terra, e seus benefícios medicinais. Arq Cienc Saúde UNIPAR, 20(3):189-194.

Milhomem, A. V., \& Teixeira, S. M. (1997). A Cultura do açafrão (Curcuma longa L.) em Goiás - Contribuições para a sustentabilidade. Pesquisa Agropecuaria Tropical.

Miranda-Matos, E. C., et al. (2012). Atlas de microscopia: café torrado e moído (Coffea sp.). Funed.

Moretes, D. N., \& Geron, V. L. M. G. (2019). Os Benefícios Medicinais da Curcuma longa L. (Açafrão Da Terra). Revista Científica da Faculdade de Educação e Meio Ambiente, 10(1):106-114.

Parvathy V. A., Swetha. V. P., Sheeja, T. E., \& Sasikumar, B. (2015). Detection of plant-based adulterants in turmeric powder using DNA barcoding. Pharmaceutical Biology, 53 (12), 1774-1779.

Reis, N., Franca, A., \& Oliveira, L. S. (2013). Performance of diffuse reflectance infrared Fourier transform spectroscopy and chemometrics for detection of multiple adulterants in roasted and ground coffee, LWT-Food Science and Technology, 53, 395-401.

Sasikuma, B. (2019) Advances in adulteration and authenticity testing of turmeric (Curcuma longa L.). Journal of Spices and Aromatic Crops, 28(2): 96-105. 
Research, Society and Development, v. 10, n. 3, e37710313333, 2021

(CC BY 4.0) | ISSN 2525-3409 | DOI: http://dx.doi.org/10.33448/rsd-v10i3.13333

Sasikumar, B., Syamkumar, S., Remya, R., \& Zachariah, T. J. (2007). PCR based detection of adulteration in the market samples of turmeric powder. Food Biotechnology, 18, 299-306.

Sem, A. R., Gupta, P. S., \& Dastidar, N. G. (1974). Detection of Curcuma zedoaria and Curcuma aromatica in Curcuma longa (turmeric) by thin-layer chromatography. Analyst, 99, 153-155.

Silva, J. C., Silva, N. A. B., Silva, S. L. R., Silva, L. S., Junqueira, M. S., \& Trombete, F. M. (2019). Avaliação microscópica e físico-química de café torrado e moído comercializado em Sete Lagoas-MG. Scientia Plena, 15:(6).

Souza-Moreira, T. M., Salgado, H. R. N.; \& Pietro, R. C. L. R. (2010). O Brasil no contexto de controle de qualidade de plantas medicinais. Rev. Bras. Farmacogn., 20(3).

Tavares, K. M., et al. (2016). Free tocopherols as chemical markers for Arabica coffee adulteration with maize and coffee by-products. Food Control, 70, 318324.

Toci, A. T., Farah, A., Pezza, H. R., \& Pezza, L. (2015). Coffee adulteration: more than two decades of research. Critical reviews in analytical chemistry, 16, 83-92.

Wang, X., Kim, J. R., Lee, S. B., Kim, Y. J., Jung, M. Y., Kwon, H. W., \& Ahn, Y. J. (2014). Effects of curcuminoids identified in rhizomes of Curcuma longa on BACE-1 inhibitory and behavioral activity and lifespan of Alzheimer's disease Drosophila models. BMC Complement Altern Med. 5, 14:88.

Windarsih, A., Rohman, A., \& Swason, R. T. (2019). Application of 1H-NMR based metabolite fingerprint and chemometrics for authentication of Curcuma longa adulterated with C. heyneana. Journal Applied Research on Medicinal and Aromatic Plants, 13, 100203.

Yu, Z. F., Kong, L. D., \& Chen, Y. (2002). Antidepressant activity of aqueous extracts of Curcuma longa in mice. Journal of Ethnopharmacology, 83(12):161-5. 